\title{
Modelagem do processo de desidratação de lodo anaeróbio em leitos de secagem simulados
}

\author{
Sérgio R. A. Soares ${ }^{1}$, Zanna M. R. de Matos $^{2} \&$ Ricardo S. Bernardes ${ }^{3}$
}

\begin{abstract}
1 UnB. SON 206 Bloco J, Apt. 506, CEP 70844-100, Brasília, DF. Fone: (61) 273-6634. E-mail: ayimoraes@hotmail.com (Foto)
2 Departamento de Engenharia Civil e Ambiental/UnB. Fone: (61) 307-2304. E-mail: zannamatos@zipmail.com.br

${ }^{3}$ Departamento de Engenharia Civil e Ambiental/UnB. Fone: (61) 307-2325. E-mail: ricardo@unb.br
\end{abstract}

Protocolo $140-16 / 11 / 2000$

\begin{abstract}
Resumo: O emprego de leitos de secagem para a desidratação de lodo de descarte de reatores UASB, constitui excelente alternativa, face a sua simplicidade operacional e aos reduzidos custos de implantação. Este trabalho apresenta uma análise dos fenômenos que influenciam o processo de desidratação de lodo anaeróbio, a partir de simulação de leitos de secagem. Neste sentido, são feitas considerações sobre as características e o comportamento do lodo durante cada fase da secagem. Sugere-se também, um modelo matemático para representar o processo de secagem, obtido a partir dos dados experimentais.
\end{abstract}

Palavras-chave: secagem de lodo, leitos de secagem, lodo anaeróbio, modelagem

\section{Anaerobic sludge dewatering process modeling in simulated drying beds}

\begin{abstract}
The employment of drying beds is an excellent option for dewatering of UASB reactor discarded sludge, because of their simple operation and low construction costs. This paper presents an anaerobic sludge dewatering process analysis of the most influential phenomenon based on drying beds simulation. Therefore, some considerations were made about sludge characteristics and behavior during each dewatering stage. A mathematical model for dewatering process representation obtained from experimental data is also suggested.
\end{abstract}

Key words: sludge dewatering, drying beds, anaerobic sludge, modeling

\section{INTRODUÇÃO}

$\mathrm{O}$ tratamento adequado de esgotos tem, como finalidade principal, corrigir as suas características indesejáveis, possibilitando que o seu uso ou disposição final possa ocorrer de acordo com as regras e critérios definidos pelas autoridades legislativas e em função da qualidade mínima exigida do efluente. Ante a necessidade da criação de sistemas simples de tratamento de esgotos, que combinassem uma alta eficiência de remoção a custos baixos de construção e operação desenvolveram-se, como alternativa, vários sistemas com base na digestão anaeróbia, dentre eles o reator anaeróbio de fluxo ascendente e manto de lodo (reator UASB).

Como todo tratamento biológico, o reator UASB produz certa quantidade de lodo, que fica acumulado em seu interior. Uma vez que a capacidade de armazenamento do reator é limitada, o lodo deve ser descartado periodicamente, a fim de evitar que seja descarregado junto com o efluente. Para redução dos custos operacionais, o lodo deve ser descartado em grandes quantidades e com menor freqüência, desde que não comprometa a performance do tratamento (Cavalcanti et al., 1999).
O lodo digerido proveniente de um reator anaeróbio apresenta cor marrom a negra, possui odor fraco e produção de gás. Além dos aspectos físicos, os constituintes químicos e propriedades do lodo que afetam a viabilidade da aplicação no solo e seu uso benéfico, também devem ser conhecidos, e incluem a matéria orgânica, os nutrientes (fósforo, nitrogênio e outros), os patogênicos, os metais pesados e componentes tóxicos (Metcalf \& Eddy, 1991). Dentre as principais características físicas e químicas médias encontradas em lodos gerados de reatores anaeróbios, pode-se enunciar: $\mathrm{pH}$ de 6,5, teor de umidade em torno de $96 \%$ e, em termos de porcentagem de sólidos totais, $2,3 \%$ de nitrogênio e $0,95 \%$ de fósforo (Andreoli \& Fernandes, 1999).

Segundo Imhoff \& Imhoff (1996) a quantidade de lodo produzido em uma estação de tratamento de esgotos é determinada pelo número de habitantes que dispõem de instalações sanitárias de coleta, cujo volume produzido é tanto maior quanto mais avançado for o grau de tratamento da estação. A partir dos dados compilados por Aisse et al. (1999) estima-se que a taxa de produção média de lodo gerado em um reator UASB é de $16 \mathrm{~g} \mathrm{STS} \mathrm{hab}^{-1} \mathrm{~d}^{-1}$, enquanto o volume diário de lodo se encontra em torno de $0,25 \mathrm{~L} \mathrm{hab}^{-1} \mathrm{~d}^{-1}$. Os mesmos dados 
indicam que a concentração de lodo em excesso do reator UASB não será inferior a $50 \mathrm{~g} \mathrm{~L}^{-1}$. Ressalta-se que, segundo van Haandel \& Lettinga (1994) em um sistema sob condições estacionárias pode-se igualar a produção de lodo do sistema à soma da massa de sólidos descarregados como lodo de excesso e de sólidos sedimentáveis no efluente.

A produção de lodo de um reator UASB pode ser considerada baixa, devido à forma de conversão da matéria orgânica em um sistema anaeróbio, sendo esta uma de suas principais vantagens. Em virtude das baixas taxas de crescimento das bactérias anaeróbias, tem-se baixa produção de sólidos biológicos, que irão constituir o lodo que deve ser descartado periodicamente. O lodo de descarte, dado ao seu elevado grau de estabilização, pode ser encaminhado sem qualquer tipo de tratamento prévio às unidades de secagem, pois possui facilidade de desidratação e, geralmente, reduzido volume, em razão de sua alta concentração. É importante que o lodo esteja bem estabilizado antes de sua aplicação nos leitos de secagem pois, caso contrário (lodo não estabilizado ou bruto) a secagem pode ocorrer muito lentamente, apresentando problemas de maus odores e possibilitando a proliferação de insetos (Ponsen \& Rooijmans, 1987).

Os processos mecânicos (ou artificiais) de desidratação do lodo necessitam de alguns pré-requisitos para que o lodo seja convenientemente desidratado. Normalmente, o lodo, após passar por um adensador, é encaminhado para o condicionamento químico, que deve ser adaptado a cada tipo de lodo, em função da sua composição físico-química e estrutural e da técnica de desidratação a ser utilizada; já os sistemas de processos naturais constituídos, basicamente, de leitos de secagem e lagoas de secagem, são bastante utilizados em sistemas de tratamento simplificados, situados em locais com clima semelhante ao do Brasil (Andreoli \& Fernandes, 1999).

Os leitos de secagem são unidades de tratamento, geralmente projetadas e construídas em forma de tanques retangulares, que têm por objetivo desidratar, por meios naturais, o lodo digerido (Jordão \& Pessoa, 1995). São operados em regime de batelada, sendo que a remoção do lodo seco, antes da aplicação de cada nova batelada, é necessária para o bom funcionamento do leito. Inicialmente, a percolação é o processo que mais contribui na remoção da água; todavia, a percolação só é viável até que o lodo atinja, aproximadamente, teor de sólidos de 20\% (Aisse et al., 1999) de modo que a evaporação é essencial para se obter lodo com teor mais elevado de sólidos.

O emprego do processo de secagem do lodo a partir de leitos de secagem, tem sido considerado a alternativa mais coerente, por motivos técnicos e econômicos, quando utilizada em estações de tratamento que empregam reatores UASB. Destaca-se, também, que a secagem natural do lodo resulta em um produto com baixo teor de água, o que facilita, sobremaneira, sua remoção e transporte, e possível ausência de patogênicos, acarretada pela exposição ao sol (van Haandel \& Lettinga, 1994). Essas considerações possibilitam a alternativa de utilização do lodo seco na agricultura; todavia, o processo de desidratação de lodo em leitos de secagem não é muito bem definido, existindo uma lacuna quanto ao perfeito entendimento dos fenômenos que englobam a secagem do lodo e dos parâmetros que possam ser tomados para o dimensionamento do leito. A própria Norma Brasileira, NBR 12209/90 (ABNT, 1990) que fixa as condições para o tratamento do lodo, não possui critérios que levem em conta as características do lodo e, tampouco, da região em que o leito de secagem vai ser construído.

Diante deste problema, o presente trabalho teve como propósito contribuir para a otimização do controle operacional de reatores UASB, ao abordar questões relativas à análise e modelagem do processo de desidratação do lodo, a partir de simulação de leitos de secagem. Assim, através dele, procura-se estabelecer indicadores que possam vir a ser utilizados em projetos, especialmente nos referentes aos aspectos de percolação e evaporação da água do lodo e também às características do lodo seco gerado.

\section{MATERIAL E MÉTODOS}

O lodo para análise, proveniente da ETE Paranoá (cidade satélite de Brasília, DF) foi obtido mediante descarte de lodo estabilizado de um dos três reatores UASB da estação de tratamento. A cidade satélite do Paranoá está localizada a leste de Brasília, DF, próximo à barragem formadora do Lago Paranoá. Atualmente, a cidade possui uma população em torno de 48.000 habitantes, sendo prevista, em projeto, uma população limite de até 60.000 habitantes (Neder \& Harada, 1997) conforme o atual esquema de urbanismo adotado. Considerando-se o valor médio de produção de lodo de $2,5.10^{-4} \mathrm{~m}^{3} \mathrm{hab}^{-1} \mathrm{~d}^{-1}$, obtido por Aisse et al. (1999) estima-se, para a cidade do Paranoá, uma produção atual mensal de $360,0 \mathrm{~m}^{3}$ de lodo.

Para a análise do processo de secagem de lodo de descarte anaeróbio, foi executado um procedimento experimental com quatro leitos de secagem em escala-piloto, para a verificação da influência da radiação e outros parâmetros nos fenômenos de percolação e evaporação do lodo, a partir do acompanhamento da umidade. Os processos de percolação e evaporação foram avaliados simultaneamente, de acordo com suas ocorrências.

Os leitos de secagem em escala-piloto foram construídos e adaptados em vasos de plástico de altura aproximada de $210 \mathrm{~mm}$ e diâmetro de superfície de $250 \mathrm{~mm}$ (diâmetro de fundo de $190 \mathrm{~mm}$ ). Nesses vasos, colocou-se uma camada de georede, seguida de uma manta geotêxtil, para atuar como malha de drenagem. A manta utilizada, com $60 \mu \mathrm{m}$ de abertura de filtração, consiste de um geotêxtil não tecido agulhado, de filamentos contínuos de puro poliéster. A área de percolação, localizada no fundo dos leitos de secagem, possuía seis aberturas localizadas em sua zona central para a passagem do líquido percolado.

Para a realização dos testes, foram dispostos $5,0 \mathrm{~L}$ de lodo em cada um dos quatro leitos de secagem, ressaltando-se que a camada de lodo possuía altura inicial de cerca de $17 \mathrm{~cm}$ e área superficial de aproximadamente $0,044 \mathrm{~m}^{2}$, enquanto a taxa de sólidos aplicada foi de $8,1 \mathrm{~kg} \mathrm{STS} \mathrm{m}^{-2}$, obedecendo aos critérios da ABNT (1990) que recomenda taxas de aplicação de até $15,0 \mathrm{~kg} \mathrm{STS} \mathrm{m}^{-2}$.

Os testes foram realizados ao ar livre, em uma área especial dotada de radiômetro (Kipp \& Zonen, 1995) para medição contínua da radiação a partir da fração de comprimento de onda UV-A e UV-B, que são as bandas de maior importância para a evaporação de água a nível do solo. As análises periódicas do teor de umidade foram realizadas de acordo com o procedimento 
experimental sugerido por Handa \& Nogueira (1998) para lodo de esgotos.

Destaca-se que o trabalho consistiu na determinação do teor de umidade durante o processo de secagem do lodo, para uma taxa aplicada $\left(8,1 \mathrm{~kg} \mathrm{STS}^{-2}\right)$, sendo esse procedimento ligeiramente diferente do usualmente adotado em experimentos com lodo. Aisse \& Andreoli (1999), Alem Sobrinho \& Samudio (1996), Lima et al. (1999) e van Haandel \& Lettinga (1994) por exemplo, optaram por realizar testes para diferentes taxas de aplicação do lodo mas, com o objetivo de analisar o processo de secagem e a influência de possíveis efeitos externos, fez-se opção por se utilizar uma taxa de aplicação constante, de modo a não se incluir mais uma variável de análise no procedimento adotado. Avaliou-se, também, a qualidade do líquido drenado nos leitos de secagem, após o processo de percolação, a partir do exame bacteriológico de coliformes fecais e coliformes totais, seguindo-se as recomendações contidas no Standard Methods (APHA, 1995).

$\mathrm{Na}$ análise do processo de secagem, foi estabelecida a correlação da variação do teor de umidade do lodo em função do tempo de exposição, a partir dos dados experimentais e estendendo os resultados para a contribuição de outros pesquisadores. Para tanto e se utilizando do programa de simulação Simnon (SSPA, 1998) propôs-se um modelo, com base em equações diferenciais, que pudesse representar a variação do teor de umidade durante a secagem do lodo.

\section{RESULTADOS E DISCUSSÃO}

A apresentação e a análise dos dados encontram-se divididas em duas abordagens, de modo a se obter maior clareza na discussão. Na primeira etapa são descritos os mecanismos do processo de desidratação do lodo anaeróbio, observados experimentalmente a partir da simulação dos leitos de secagem, identificando-se seus principais fatores de influência. $\mathrm{Na}$ seqüência, em uma segunda etapa estão apresentadas as equações originadas a partir da aplicação do modelo de ajuste e, como conseqüência, a curva de secagem de lodo, contendo o teor de umidade da amostra em função do tempo de exposição.

A Figura 1 apresenta, de forma esquemática, as diferentes fases (I a IV) verificadas durante o processo de secagem do lodo anaeróbio. No experimento, considerou-se a amostra de lodo com teor de umidade inferior a $10 \%$, como totalmente seca.

Durante o processo de secagem dois fenômenos distintos foram observados, sendo preponderantes em fases diferentes: a drenagem (ou percolação) e a evaporação da água de lodo.

A água no lodo pode existir em quatro formas (Vesilind \& Hsu, 1997): água livre (que não se encontra agregada à fase sólida e pode ser separada simplesmente por gravidade); água adsorvida; água capilar e água celular, em que estas últimas, para serem removidas, necessitam de forças mecânicas ou de uma mudança do estado de agregação da água como, por exemplo, por meio de evaporação ou congelamento.

Como grande parte da água do lodo é livre, pode ser removida a partir do processo de percolação, cujo período é relativamente curto, se comparado com a duração total da secagem do lodo. $\mathrm{Na}$ fase I (Fig. 1) que caracteriza o início da secagem do lodo, percebese que a percolação foi o fenômeno dominante, prolongando-se até a fase II (Fig. 1) que ocorreu por volta de $2 \mathrm{~d}$.

Quando o lodo foi descarregado sobre o leito de secagempiloto, a água foi removida essencialmente por percolação. Após a ocorrência desse processo, o fluido inicial do lodo aplicado se transformou em uma massa pastosa e densa, na qual não se verificou mais a drenagem. Nessa etapa, o lodo apresentou teor de umidade em torno de $80 \%$, verificado neste experimento, e confirmado por van Haandel \& Lettinga (1994) em teste de secagem de lodo anaeróbio para diferentes taxas de aplicação. Aisse et al. (1999) também limitaram a viabilidade da percolação a este patamar de umidade do lodo. A partir disso, pode-se inferir sobre a influência do lodo e da soleira drenante na percolação e identificar o fator determinante para o estabelecimento desse limite, pois independente da fração de sólidos do lodo inicial, da carga aplicada e do tempo de exposição do lodo, em que o teor de umidade de $80 \%$ foi verificado após a drenagem.
I
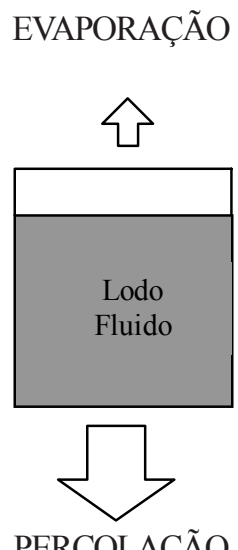

PERCOLAÇÃO

$\mathrm{t}=0$

Umidade $\cong 95 \%$
II
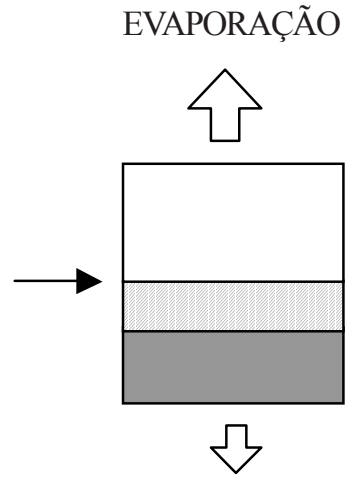

PERCOLAÇÃO

$$
\mathrm{t}=2 \mathrm{~d}
$$

Umidade $=\varnothing 0 \%$
III

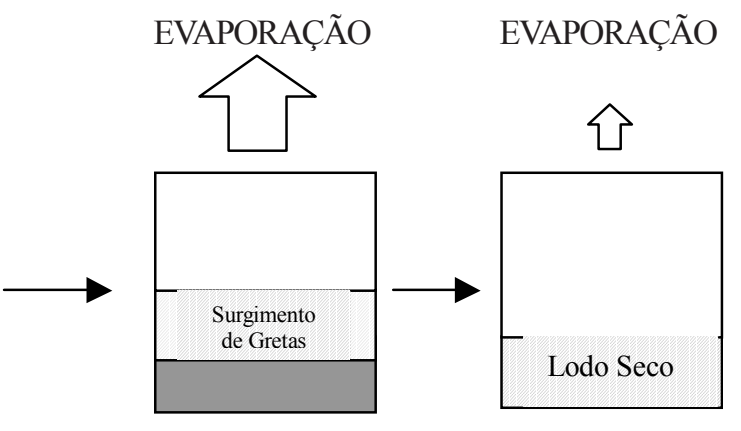

PERCOLAÇÃO

$$
\mathrm{t}=2 \mathrm{a} 8 \mathrm{~d}
$$

Umidade $\cong 50$ a $80 \%$
IV

EVAPORAÇÃO

PERCOLAÇÃO

$$
\mathrm{t}=15 \mathrm{~d}
$$

Umidade $\cong 10 \%$

Figura 1. Desenho esquemático do processo verificado experimentalmente, de secagem de lodo anaeróbio, ao longo do tempo 
Neste experimento, ao contrário do preconizado pela ABNT (1990) foram empregadas mantas geotêxteis para representar, de forma adequada, o material drenante. Mesmo com essa alternativa, o fenômeno percebido desenvolveu-se dentro da expectativa, com a drenagem do líquido ocorrendo entre o primeiro e o segundo dias, e alcançando, ao final do processo, o teor de umidade esperado de $80 \%$.

Lima et al. (1999) utilizaram, em procedimento experimental similar, o mesmo material especificado pela referida Norma como soleira drenante dos leitos de secagem, tendo obtido também, logo no primeiro dia, valores elevados relativos ao volume de líquido percolado. Ao colocarem camadas de cascalho e areia como soleira drenante, van Haandel \& Lettinga (1994) não obtiveram resultados que alterassem os efeitos do processo de percolação. Esses resultados sugerem que as propriedades do lodo, independente da concentração de sólidos ou da carga aplicada, são responsáveis por estabelecerem o limite do processo de percolação, ao atingir, nos casos verificados, o mesmo teor de umidade final.

A Norma 12209/90 (ABNT, 1990) diz que, no caso do emprego de processos mecanizados de desidratação do lodo, o líquido separado deve retornar ao processo de tratamento da fase líquida, em cujo dimensionamento deve ser considerada a carga correspondente. A mesma Norma, no entanto, não faz referência à recirculação do percolado proveniente de leitos de secagem, razão por que essa questão deve ser vista com cautela, pois a análise bacteriológica de amostra do percolado, para detecção do grupo coliforme, apresentou os seguintes resultados para coliformes totais $(\mathrm{CT})$ e coliformes fecais $(\mathrm{CF})$, respectivamente: $\mathrm{CT}=4,6.10^{5} \mathrm{e} \mathrm{CF}=3,54.10^{5} \mathrm{NMP} 100 \mathrm{~mL}^{-1}$.

Embora esses organismos indicadores de contaminação fecal não sejam patogênicos, sua presença é indicação de que a água apresenta contaminação por fezes humanas ou de animais e, como conseqüência, a sua potencialidade, para transmitir doenças. Desta forma, é necessária a devida precaução quanto ao destino final da água de lodo drenada. Como medida preventiva, espera-se que essa água seja conduzida ao sistema de tratamento de esgotos ou sofra outro destino final sanitariamente adequado.

Como discutido anteriormente, quando o lodo atingiu teor de umidade de aproximadamente $80 \%$, a percolação cessa ou passa a ocorrer de modo pouco significativo; portanto, a partir desse momento somente a evaporação passa a influir, sendo o fenômeno dominante, como pode ser observado nas fases II a IV (Fig. 1). Neste sentido, para a análise da influência da evaporação e o conseqüente decréscimo do teor de umidade do lodo em leitos de secagem, deve ser observada a influência da radiação, procurando-se estabelecer uma correlação entre a incidência de radiação e a secagem do lodo. A quantidade de energia de radiação capturada na superfície (neste caso do lodo) é o fator dominante que controla as taxas regionais de evaporação; assim, a utilização de variáveis regionais, como a temperatura e, principalmente, a radiação, é fundamental para o perfeito entendimento e avaliação de um processo que tenha a evaporação como principal fenômeno (Shuttleworth, 1993).

Durante o período do experimento foi verificada, com os dados do radiômetro, uma incidência média de radiação de $650 \mathrm{cal} \mathrm{cm}^{-2}$, obtida em uma faixa de variação de $500 \mathrm{a} 750 \mathrm{cal} \mathrm{cm}^{-2}$ em todos os dias. De posse desses valores, percebe-se que a radiação foi praticamente uniforme ao longo do tempo, o que leva à suposição de que ela não constitui fator decisivo para o incremento da evaporação da água de lodo, isto é, a radiação atua de forma constante. A partir do momento em que o lodo atingiu teor de umidade inferior a $80 \%$, percebeu-se que o processo de secagem evoluiu mais lentamente, com o surgimento de duas camadas distintas no leito de secagem (fases II e III na Fig. 1), uma camada inferior úmida (com umidade praticamente constante e próxima a $80 \%$ ) e uma camada superior seca, exposta à influência direta da radiação.

Desta forma, a camada de lodo que se encontra diretamente em contato com a atmosfera tende a secar de forma mais eficiente, formando a camada seca na superfície a qual, quando de sua formação, passou a funcionar como uma espécie de barreira, que praticamente impediu a incidência de radiação e limitou a evaporação da água de lodo na camada inferior, próximo à soleira drenante. Para confirmação desse fato verificaram-se, no mesmo instante, em um mesmo leito de secagem, dois teores de umidade distintos, $55 \%$ na camada seca superficial e $76 \%$ na camada úmida inferior, no sexto dia de experimento, mas a partir do aparecimento das gretas (fase III, Fig. 1) ocorreu aceleração do processo de evaporação, com conseqüente redução do conteúdo de água, tornando a secagem mais eficiente. O conteúdo de água influencia as propriedades mecânicas do lodo (Chu \& Lee, 1999; van Haandel \& Lettinga, 1994): com a diminuição da umidade, em termos gerais, o lodo perde as características de um fluido e se transforma em uma torta semi-sólida, e depois em um sólido, já com volume reduzido. A evolução das gretas de contração pode ser vislumbrada na Foto 1.
(A)

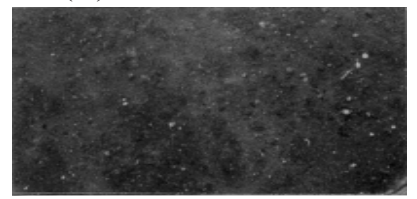

(C)

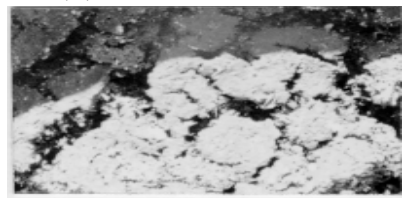

(B)

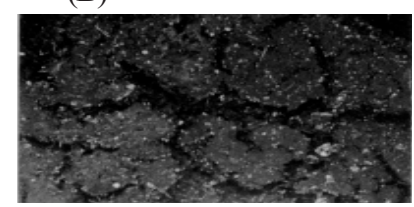

(D)

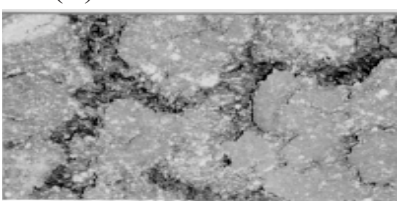

Foto 1. Detalhes da evolução do gretamento da camada de lodo na superfície dos leitos de secagem: (A) com $95 \%$ de umidade em $\mathrm{t}=0$; (B) e (C) com 75\% de umidade em $\mathrm{t}=3 \mathrm{~d}$; e (D) com $55 \%$ de umidade $\mathrm{em} \mathrm{t}=6 \mathrm{~d}$

O fenômeno do gretamento, também evidenciado por Bierck \& Dick (1990) pode ser considerado análogo ao que ocorre em solos argilosos. A diminuição do volume, ou contração, durante o processo de secagem, é causada por forças de capilaridade que provocam uma distribuição característica de gretas de contração na superfície da camada originalmente líquida (Koorevar et al., 1983). As gretas são produzidas pela resistência a contração, oferecida pela superfície inferior de cada camada que seca, sendo que a contração ocorre proporcionalmente ao volume de água removido pela evaporação, até um ponto de 
equilíbrio (Baver et al., 1972). Desta forma e no caso do lodo e na ausência de precipitação, o gretamento permite um efeito maior da evaporação. As gretas, principalmente no estágio (D) da Foto 1, contribuem para o aumento significativo da área exposta ao ar livre, incrementando a influência da evaporação para uma mesma contribuição de radiação.

Além dessas considerações a respeito do processo de secagem do lodo, fez-se uma avaliação experimental a partir do acompanhamento dos valores do teor de umidade ao longo do tempo para os quatro leitos de secagem do experimento; assim, os dados de umidade do lodo foram utilizados para ajuste do modelo de simulação matemática Simnon, obtendo-se equações para representar os fenômenos de percolação e evaporação observados durante a secagem do lodo. Como seqüência, o teor de umidade da camada de lodo superficial como função do tempo de exposição (ou duração do processo de secagem) está apresentado na Figura 2. A equação de perda de umidade com drenagem da água no lodo, foi obtida por:

$$
\frac{\mathrm{dP}_{\mathrm{d}}}{\mathrm{dt}}=\mathrm{K}_{\mathrm{d}}\left(\mathrm{U}-\mathrm{C}_{\mathrm{C}}\right)
$$

donde:

$\mathrm{P}_{\mathrm{d}} \quad$ - perda de umidade devido à drenagem, $\%$

$\mathrm{K}_{\mathrm{d}} \quad$ - coeficiente de proporcionalidade de drenagem, $\mathrm{d}^{-1}$

$\mathrm{U}$ - umidade do lodo, $\%$

$\mathrm{C}_{\mathrm{C}}$ - capacidade de campo do lodo, $\%$ de umidade

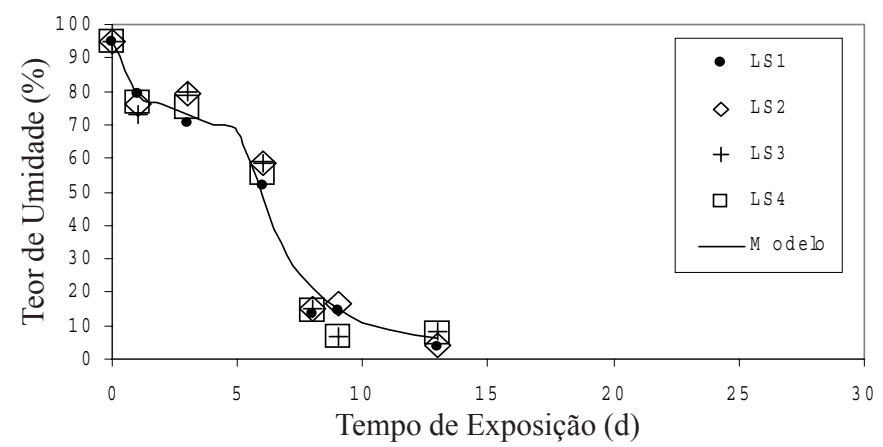

Figura 2. Teor de umidade (\%) em função do tempo de exposição (d) e curva de secagem ajustada a partir dos dados experimentais

No ajuste do modelo obteve-se um coeficiente de proporcionalidade de drenagem $\left(\mathrm{K}_{\mathrm{d}}\right)$ igual a $5 \mathrm{~d}^{-1}$. A partir da verificação experimental e dos resultados obtidos por van Haandel \& Lettinga (1994) e Aisse et al. (1999) o teor de umidade que caracteriza a capacidade de campo do lodo foi fixado em $80 \%$ e definido como o limite de umidade de lodo em que atua o fenômeno de percolação. A partir desse ponto, a evaporação passa a agir como processo dominante responsável pela secagem do lodo. A equação abaixo representa a perda de umidade do lodo devido à evaporação em função do tempo:

$$
\frac{\mathrm{dP}_{\mathrm{e}}}{\mathrm{dt}}=\mathrm{K}_{\mathrm{e}}\left(\mathrm{U}-\mathrm{U}_{\min }\right)
$$

em que:

$\mathrm{P}_{\mathrm{e}} \quad$ - perda de umidade devido à evaporação, \%

$\mathrm{K}_{\mathrm{e}} \quad$ - coeficiente de proporcionalidade na evaporação, $\mathrm{d}^{-1}$

U - umidade do lodo, $\%$

$\mathrm{U}_{\min }$ - umidade mínima do lodo, \%
Neste trabalho foi considerado o teor de umidade de 5\% como a umidade mínima do lodo pois, apesar de ser esperado, para lodos em leitos de secagem, um teor de umidade mínimo de $10 \%$, foram verificados, neste experimento e também por outros autores (van Haandel \& Lettinga, 1994) valores inferiores a esse patamar, donde se conclui que o valor de $5 \%$ foi adotado no intuito de melhor representar os valores práticos obtidos. O coeficiente de proporcionalidade na evaporação foi determinado pela seguinte equação:

$$
\mathrm{K}_{\mathrm{e}}=\alpha \beta \frac{\mathrm{R}}{\mathrm{h}_{\mathrm{i}}}
$$

em que:

$\mathrm{K}_{\mathrm{e}} \quad$ - coeficiente de proporcionalidade na evaporação, $\mathrm{d}^{-1}$

$\alpha$ - coeficiente de proporcionalidade no gretamento, adimensional

$\beta \quad$ - coeficiente de proporcionalidade para radiação, $\mathrm{cm}^{3} \mathrm{cal}^{-1}$

$\mathrm{R}$ - radiação total, cal $\mathrm{cm}^{-2} \mathrm{~d}^{-1}$

$\mathrm{h}_{\mathrm{i}} \quad$ - altura inicial de lodo, $\mathrm{cm}$

Os valores dos coeficientes são: $\alpha=1$ para $U>67 \%$ passando para $\alpha=12$ quando $U<67 \%$ e $\beta=1,077.10^{-3}$, determinados a partir do ajuste do modelo proposto aos dados experimentais. Para uma radiação diária média de $650 \mathrm{cal} \mathrm{cm}^{-2}$ (obtida experimentalmente com os dados do radiômetro) e altura inicial de lodo de $17 \mathrm{~cm}$, obtém-se o coeficiente de proporcionalidade na evaporação igual a $0,494 \mathrm{~d}^{-1}$.

De posse das equações anteriores, pode-se expressar a equação geral do teor de umidade do lodo em função do tempo, a partir das perdas por drenagem e evaporação. Nessa equação geral, mostrada a seguir, leva-se em consideração o ganho de umidade resultante de uma possível precipitação durante o período de secagem do lodo.

$$
\mathrm{U}=\mathrm{U}_{\mathrm{i}}-\mathrm{P}_{\mathrm{d}}-\mathrm{P}_{\mathrm{e}}+\mathrm{U}_{\mathrm{p}}
$$

donde :

U - umidade do lodo no tempo t, $\%$

$\mathrm{U}_{\mathrm{i}} \quad$ - umidade inicial do lodo, $\%$

$P_{d} \quad$ - perda total de umidade por drenagem no tempo t, \%

$\mathrm{P}_{\mathrm{e}}$ - perda total de umidade por evaporação no tempo t, $\%$

$\mathrm{U}_{\mathrm{p}} \quad$ - acréscimo total de umidade por precipitação no tempo $\mathrm{t}, \%$

A umidade inicial do lodo pode ser considerada em torno de $95 \%$. No decorrer do experimento não ocorreu acréscimo de umidade por precipitação, pois não houve chuvas no período. Não obstante, um possível acréscimo de umidade devido à precipitação deve produzir um deslocamento na curva de secagem, com o lodo adquirindo teor de umidade superior.

A partir desse novo patamar, o lodo tende a passar novamente por todo o processo de secagem. Destaca-se, entretanto, que esta não é uma relação direta e que tal consideração não se refere ao volume de água precipitada e, sim, ao ganho de umidade do lodo pois, como enfatizado por van Haandel \& Lettinga (1994) a precipitação pluviométrica não é removida com a mesma taxa que a água de lodo; assim, grande parte do volume de água precipitado percola rapidamente pelo leito, não se distribuindo no lodo. No caso da existência 
de sobrenadantes no leito de secagem, provenientes da ocorrência de chuvas, Alem Sobrinho \& Samudio (1996) recomendam a implantação de dispositivos de remoção.

Com o intuito de se verificar a validade do modelo proposto de curva de secagem para diferentes taxas de aplicação, incorporaram-se os dados experimentais de van Haandel \& Lettinga (1994) para lodo de descarte de reatores UASB, e se fez a simulação das curvas de secagem. Para tanto, foi modificado apenas o valor da altura inicial do lodo $\left(h_{i}\right)$ uma vez que esta variação representa, em uma mesma área superficial, o aumento da carga de sólidos aplicada. Apesar da necessidade de reavaliação da influência do gretamento, após a mudança da altura inicial do lodo $\left(h_{i}\right)$ e das diferentes condições climáticas, optou-se por não se modificar os demais parâmetros, de modo a ser verificada a adequação do modelo com o mínimo de alterações possíveis. As curvas de secagem obtidas para as cargas de 9,7; 18,0;26,5;36,0; e 45,7 $\mathrm{kg} \mathrm{STS} \mathrm{m}^{-2}$, estão apresentadas na Figura 3.

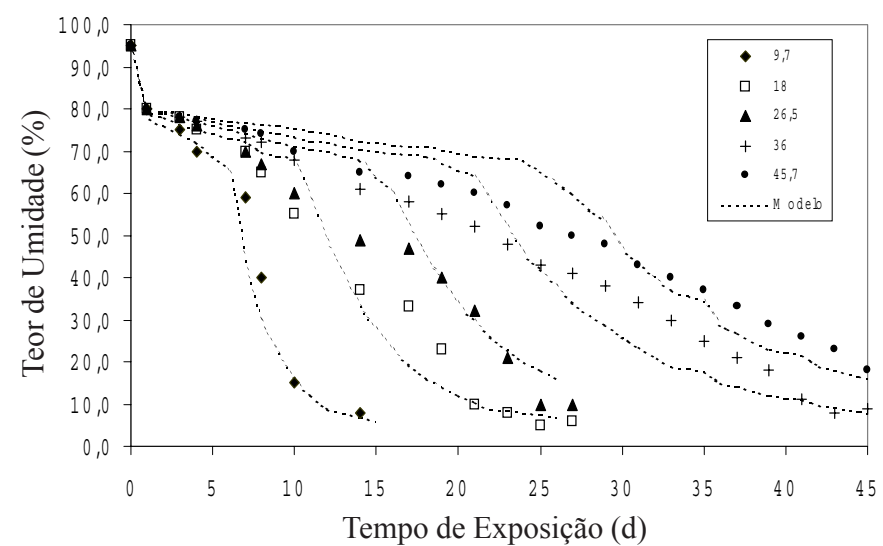

Figura 3. Teor de umidade em lodo para diferentes cargas de sólidos, em função do tempo de exposição (dados de van Haandel \& Lettinga, 1994) e curvas de secagem, obtidas a partir do modelo de secagem adaptado, considerando-se as diferentes alturas iniciais de lodo

Verifica-se, na Figura 3, que existe boa correlação entre o modelo proposto e os dados experimentais, principalmente para os valores mais baixos de taxas de aplicação, adequados para leitos de secagem, devido o fato do modelo ter sido produzido para uma taxa de $8,1 \mathrm{~kg} \mathrm{STS} \mathrm{m}^{-2}$, provocando extrapolação cada vez maior a medida em que se aumentavam os valores das cargas aplicadas.

De fato, as maiores cargas aplicadas não são adequadas para a operação de leitos de secagem, tanto que a NBR 12209/90 (ABNT, 1990) recomenda taxas de aplicação de até $15,0 \mathrm{~kg} \mathrm{STS} \mathrm{m}{ }^{-2}$. Com efeito, as taxas de aplicação mais elevadas são compatíveis com lagoas de lodo pois, devido às suas características construtivas e operacionais, retardam os efeitos do processo, constituindo-se em unidades de longo período de secagem. As lagoas de secagem têm finalidade e funcionamento semelhantes aos leitos de secagem, dos quais diferem fundamentalmente, no que se refere ao sistema de drenagem, pouco eficiente no caso das lagoas. Com isto, o ajuste para as maiores cargas aplicadas, resultantes do aumento da altura inicial de lodo, indica que o modelo também pode descrever o comportamento do lodo nessa situação, que é o caso de lagoas de secagem, desde que se façam as modificações necessárias com relação às particularidades operacionais e aos detalhes construtivos.

Mesmo se levando em consideração que não foram feitas modificações no modelo, o resultado obtido se mostrou bastante satisfatório, sugerindo que o modelo apresentado pode servir para representar o processo de secagem ressaltando-se entretanto, que, dependendo da situação e das características da região, alguns ajustes se fazem necessários, pois são importantes na medida em que o modelo retrata uma tendência observada existindo, pois, a necessidade do seu aprimoramento para que se possa contemplar, de forma mais precisa, todas as condições particulares da desidratação de lodo anaeróbio, em leitos e lagoas de secagem.

\section{CONCLUSÕES}

1. O procedimento experimental apresentou grande eficiência na redução do volume de lodo, obtendo-se teor de umidade final inferior a $10 \%$, sugerindo que o emprego de leitos de secagem para a remoção de água do lodo de descarte de reatores UASB, pode mostrar-se bastante viável.

2. O modelo proposto para a curva de secagem mostrou-se bem ajustado aos pontos experimentais representando, adequadamente, os fenômenos de percolação e evaporação e apresentando boa adaptação as taxas de aplicação de lodo recomendadas para leitos de secagem.

3. A análise da drenagem da água de lodo permitiu identificar-se o teor de umidade de $80 \%$ como a capacidade de campo do lodo caracterizando, neste ponto, o momento em que a drenagem pára de influir e a evaporação passa a ser o fenômeno dominante.

4. A presença de coliformes fecais e totais na água de lodo drenada sugere maiores cuidados quanto à disposição final do líquido percolado.

5. A análise da secagem do lodo permitiu associar-se a influência das gretas de contração no incremento da evaporação, sendo estas, possivelmente responsáveis pela rapidez e pelo completo desenvolvimento do processo de secagem.

6. O aprimoramento dos diversos parâmetros estabelecidos nas equações do modelo proposto, de modo a incorporar as características específicas de cada região e as diferentes cargas aplicadas de lodo, e a apresentação dessas equações em um gráfico ou ábaco, possibilitou a generalização do uso do modelo para o projeto de leitos e lagoas de secagem.

\section{LITERATURA CITADA}

ABNT. Associação Brasileira de Normas Técnicas. Projeto de estações de tratamento de esgoto sanitário. Rio de Janeiro, RJ, NBR - 12209, 1990. 11p.

Aisse, M.M.; Andreoli, F. de N. Estudo da desidratação do lodo anaeróbio, obtido em reatores tipo RALF, através do uso de leitos de secagem e de centrífuga tipo decanter. SANARE: Revista Técnica da Sanepar, Curitiba, PR, v.11, n.11, p.37-43, 1999.

Aisse, M.M.; van Haandel, A.C.; von Sperling, M.; Campos, J.R.; Couracci Filho, B.; Alem Sobrinho, P. Tratamento e destino final do lodo gerado em reatores anaeróbios. In: Campos, J.R. (coord.). In: Tratamento de esgotos sanitários por processo anaeróbio e disposição controlada no solo. ABES, Rio de Janeiro, RJ, 1999. cap. 11, p.271-299. 
Alem Sobrinho, P.; Samudio, E.M.M. Desidratação de lodos de reator UASB em leitos de secagem: determinação de parâmetros. In: Congreso Interamericano de Ingeniería Sanitaria y Ambiental, 25. México, D.F., 1996.9p.

Andreoli, C.V.; Fernandes, F. (coords.). Manual prático para a compostagem de biossólidos. Rio de Janeiro, RJ: ABES, 1999. 84p.

APHA. American Public Health Association. Standard methods for the examination of water and wastewater. $19^{\mathrm{a}} \mathrm{ed}$, Washington, USA: APHA, 1995. p.9.44-9.66.

Baver, L.D.; Gardner, W.H.; Gardner, W.R. Soil physics. New York, USA: John Wiley \& Sons, Inc., 1972. 498p.

Bierck, B.R.; Dick, R.I. Mechanism of compressible sludge cake shrinkage. Journal of Environmental Engineering, ASCE, Reston, v.116, n.4, p.663-682, 1990.

Cavalcanti, P.F.F.; Medeiros, E.J.S.; Silva, J.K.M.; van Haandel, A. Excess sludge discharge frequency for UASB reactors. Water Science \& Technology, Oxford, v.40, n.8, p.211-219, 1999.

Chu, C.P.; Lee, D.J. Moisture distribution in sludge: Effects of polymer conditioning. Journal of Environmental Engineering, ASCE, Reston, v.125, n.4, p.340-345, 1999.

Handa, R.M.; Nogueira, A. Determinação de umidade a $65^{\circ} \mathrm{C}$ em amostras de lodo de esgoto. In: Andreoli, C.V.; Bonnet, B.R.P. (coords). Manual de métodos para análises microbiológicas e parasitológicas em reciclagem agrícola de lodo de esgoto. Sanepar, Curitiba, PR, 1998. p.73-74.

Imhoff, K.; Imhoff, K.R. Manual de tratamento de águas residuárias. São Paulo, SP: Ed. Edgard Blusher Ltda., 1996.301p.

Jordão, E.P.; Pessoa, C. Tratamento de esgotos domésticos. Rio de Janeiro, RJ: ABES, 1995. 683p.

Koorevar, P.; Menelik, G.; Dirksen, C. Elements of soil physics. Amsterdam, The Netherlands: Elsevier, 1983. 230p.
Kipp \& Zonnen. Instruction manual - CUVA1/CUVB1 scientific narrowband UV radiometer global radiation. Delft, The Netherlands: International Institute for Hydraulic and Environmental Engineering, 1995.

Lima, M.R.P.; Müller, P.S.G.; Gonçalves, R.F. Taxa de aplicação de lodo de lagoas anaeróbias de estabilização para desidratação em leitos de secagem. In: Congresso Brasileiro de Engenharia Sanitária e Ambiental, 20. Rio de Janeiro, RJ: ABES, 1999. p.412-421.

Metcalf \& Eddy. Wastewater engineering: Treatment, disposal and reuse. $3^{\text {a }}$ ed., New York, USA: Metcalf \& Eddy, Inc. 1991. $1334 \mathrm{p}$.

Neder, K.D.; Harada, A.L. Projeto da estação de tratamento de esgotos do Paranoá - UASB compartimentado seguido de lagoa de alta taxa e escoamento no solo. In: Congresso Brasileiro de Engenharia Sanitária e Ambiental, 19. Foz do Iguaçu, PR: ABES, 1997. p.719-726.

Ponsen, R.A.; Rooijmans, P.J. The treatment and disposal of sewage sludges - course notes. Delft, The Netherlands: International Institute for Hydraulic and Environmental Engineering, 1987.65p.

Shuttleworth, W.J. Evaporation. In: Maidment, D.R. (ed.). Handbook of Hydrology. New York, USA: McGraw-Hill, Inc., 1993.

SSPA. Simnon for Windows, V. 3.0. Göteborg, Sweden: SSPA Maritime Consulting AB, 1998.

van Haandel, A.; Lettinga, G. Tratamento anaeróbio de esgotos: Um manual para regiões de clima quente. Campina Grande, PB, 1994.

Vesilind, P.A.; Hsu, C-C. Limits of sludge dewaterability. Water Science \& Technology, Oxford, v.36, n.11, p.87-91, 1997. 